\title{
Reliability-based design of reinforced concrete beams for simultaneous bending, shear, and torsion loadings
}

\author{
Faezeh Jafari \\ Malayer University, Iran \\ Faeze_jafari666@yahoo.com \\ Jalal Akbari* \\ Bu-Ali Sina University, Hamedan, Iran \\ j.akbari@basu.ac.ir
}

\begin{abstract}
The design of Structural members is targeted in resisting the loads such that the safety of the structure is preserved regarding different conditions of loadings. The traditional design method in concrete standards is based on the load and resistance factors regardless of the random nature of them. Uncertainties in design parameters such as load and resistance have great influences in the safety of the structure and using constant coefficients caused unsafe and uneconomical designs. The present research is focused on a probabilistic design of reinforced concrete beams subjected to simultaneous actions of bending, shear, and torsion. For this purpose, analytical formulas for the limit states have been developed to combine different stresses. Monte Carlo simulation method is used to estimate the safety indexes for three different $\mathrm{T}$, rectangular and $\mathrm{L}$-shaped cross-sections. Then, the load and resistance factors have been calculated in different safety indexes, and the influence of load and resistance factors based-on ACI standard has been examined. The proposed method is applicable to all concrete standards. However, here the procedures are based on the ACI standard.
\end{abstract}

KEYwords. Reliability-Based Design; Reinforced Concrete Beam; Safety Index; Load and Resistance Factors; Monte-Carlo Simulation.

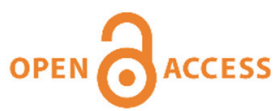

Citation: Jafari, F., Akbari, J., Reliabilitybased design of reinforced concrete beams for simultaneous bending, shear, and torsion loadings, Frattura ed Integrità Strutturale, 51 (2020) 136-150.

Received: 29.08.2019

Accepted: 07.11.2019

Published: 01.01.2020

Copyright: (C) 2020 This is an open access article under the terms of the CC-BY 4.0, which permits unrestricted use, distribution, and reproduction in any medium, provided the original author and source are credited.

\section{INTRODUCTION}

eliability method as a probabilistic design approach that was proposed for the first time by Ellingwood in1974, and then many efforts were carried out in order to employ uncertainties and probability of parameters in current design methods [1]. For instance, Evan et al [2] calculated the shear force of reinforced concrete beam in ACI regulation using new methods of reliability in 2006. The conducted researches in this field indicate this important issue that the various factors are effective in the failure of concrete beams. These factors are the ratio of the span length over effective depth, ratio of longitudinal steel, support conditions, loading conditions, and materials properties. The performance of a concrete beam in the laboratory on the basis of the statistical methods was studied. In 2013, Porco et al [3] studied the 
punching shear using the reliability method in a flat slab. Their study was focused on the evaluation of the compressive strength of the flat slab and its effective factors. Moreover, in 2014 Daniel Jensen [4] was carried out research to obtain the reliability index to show the effect of shear forces and reinforcement of concrete bridges. He showed that the use of this method was made the design $10 \%$ to $15 \%$ lighter. In 2014, Bakers et al [5] examined the reliability of concrete bridge in which the studied beam was under the effect of the moment and shear forces. There are also numerous researches were conducted by different researchers regarding the concrete safety index, including research by Nowak et al [6]. The authors estimated the safety index in their research to investigate the uncertainty parameters in various materials such as high strength concrete, normal concrete, and light concrete by taking into account various concrete structures such as slabs, beams, and columns. In 2013, [7] Uva et al proposed a seismic assessment of in-situ concrete on buildings such that concrete resistance can be evaluated by a novel CDD method to considering the effect of random parameters [7]. Pérez-Rocha (2013) was used the uncertainty method to examine better design and safety of the structures, including beam, column, and wall in Mexico regulation. The calibration of design codes was based on the coefficients existing in regulations [8]. Later on, in 2014, Abejide examined the effects of uncertainties in the safety of section for three flexure, shear and axial compression states in ACI 318-11 standard by considering the random nature of the parameters for reinforced concrete[9]. Al-Ansari et al applied experimental and numerical methods (FEM) in order to study the flexural behavior of T and rectangular concrete beams. Their experimental study was compared with the FEM analysis results for verifying the FEM code, which showed that the FEM result of rectangular beam is more safer than an experimental result for T-beam[10]. Bastidas et al in 2018 studied the combined effects of chloride-induced corrosion, climate change and cyclic loading with a stochastic model.The results of this study show that the climate change lifetime of structure by roughly $1.4-2.3 \%$ [11]. Jafari et al studied the safety index of Iranian Concrete Standard for bending, shear and torsion state using Monte Carlo simulation. In their research, the safety surface for T, L, and rectangular beams obtained and compared with together [12]. Akbari and Jafari studied the reliability behavior of concrete beam ( $T$, L, and rectangular shape) under bending conditions using Monte Carlo simulation. The beta indexes, load resistance factors, and strength reduction factors were obtained for different sections[13]. As well, Slowik et al applied a probabilistic approach to the reliability analysis of longitudinally reinforced concrete beams [14]. Huang et al in 2019 studied the flexural behavior of FRP-Strengthened reinforced concrete beams using the ultimate limit state method. According to the result of this research, the probability of failure is different for each failure mode and reduction resistance has a significant influence on concrete behavior [15].

Comprehensive literature has been published on the reliability-based design of concrete structures. As well, extensive researches were accomplished for safety index calculations; no single study exists, which computes the load and resistance factors that related to the specified safety index. Therefore, to our knowledge, detailed studies for calibration of the load and resistance factors were not reported throughout the literature. Accordingly, in this investigation, the load and resistance, loading factors for all main loadings are calculated for any desired safety index and any loading ratios. Consequently, the methodology of the present paper could be used on the design of the beams under bending, shear, and torsion loadings for a fully probabilistic based approach for all design codes. As a sample, the safety index for ACI concrete standard [16] for three limit states of shear, bending and torsion and also for the combination of the above-mentioned limit states are carried out. To achieve this, the safety indexes were obtained by introducing uncertainty factors in beam design equations and applying the Monte-Carlo simulation method. Then, various limit states function such as (shear, torsion, and bending) were assumed and the safety indexes and the load resistance factors which were addressed in the ACI standard.

\section{METHOD OF RESEARCH}

$\mathrm{I}$

n order to calculate the safety index, the limit functions which show the structural effects should be obtained. Eqns. 13 are used to calculate bending, shear, and tensional action on the beams.

$$
\begin{aligned}
& M_{r}=A_{s} * f_{y} *\left(d-\frac{A_{s} * f_{y}}{1.7 * f_{c} * b^{* d}}\right), M_{s}=M_{\text {dead load }}+M_{\text {live load }} \\
& V_{r}=0.16 \sqrt{f_{c}^{\prime}} * b_{w} * d+f_{y} * A_{v} * \frac{d}{s}, V_{s}=V_{\text {dead load }}+V_{\text {live load }}
\end{aligned}
$$




$$
T_{r}=2 * A_{0} * A_{t} * \frac{f_{y}}{s}, T_{s}=T_{\text {dead load }}+T_{\text {live load }}
$$

In Eqns. (1) to (3), $M_{r}, V_{r}$ and $T_{r}$ are the bending resistance, the shear resistance, and the torsion resistance of the crosssections, respectively. Furthermore, the parameters of $A_{s}, f_{y}, f_{c}, b, d$ refer to areas of longitudinal steel, the yield strength of steel, 28-day compressive strength of concrete, width and effective depth of the cross-sections, respectively. The nominal values of the steel are calculated according to ACI 318M-14.2015 standard[16]. For L and T shaped sections, the proposed equations are obtained [12]. To express the shear and torsion limit state functions, all sections of $\mathrm{L}, \mathrm{T}$, and rectangular shapes of concrete beams are considered. The factors considered in the ACI standard are: concrete strength reduction factor $\left(\varnothing_{c}=0.90\right)$, dead load increase factor $\left(\gamma_{D}=1.20\right)$ and live load resistance factor $\left(\gamma_{L}=1.60\right)$. In addition, the steel strength reduction factor of steel is $\varnothing_{s}=0.90$. Tab. 1 shows the statistical information (mean, covariance and probability density function(pdf)) which are used to obtain the safety indexes.

\begin{tabular}{|c|c|c|c|c|}
\hline $\begin{array}{l}\text { Standard } \\
\text { deviation }\end{array}$ & Mean & $\mathrm{pdf}$ & $\begin{array}{c}\text { Value of } \\
\text { parameters }\end{array}$ & $\begin{array}{c}\text { Random } \\
\text { parameters }\end{array}$ \\
\hline $0.18-20$ & 19.3 & Normal & 21 & $\mathrm{f}_{\mathrm{c}}^{\prime}(\mathrm{MPa})$ \\
\hline 0.12 & 472.5 & Normal & 420 & $\mathrm{f}_{\mathrm{y}}(\mathrm{MPa})$ \\
\hline $\mathrm{b} / 10$ & b & Normal & $\mathrm{b}$ & Dimension \\
\hline $\begin{array}{l}\mathrm{h} / 17 \\
\mathrm{~d} / 15\end{array}$ & $\begin{array}{l}\mathrm{h} \\
\mathrm{d}\end{array}$ & & $\begin{array}{l}\mathrm{h} \\
\mathrm{d}\end{array}$ & $(\mathrm{mm})$ \\
\hline $\begin{array}{l}0.03-0.05 \\
0.03-0.05 \\
0.03-0.05\end{array}$ & $\begin{array}{l}A_{s} \\
A_{v} \\
A_{t}\end{array}$ & Normal & $\begin{array}{l}A_{s} \\
A_{v} \\
A_{t}\end{array}$ & Area $\left(\mathrm{mm}^{2}\right)$ \\
\hline $\begin{array}{c}0.1 \\
0.40-0.25\end{array}$ & $\begin{array}{l}1.05 \mathrm{D} \\
\mathrm{L}\end{array}$ & Normal Gamble & $\begin{array}{l}\mathrm{D} \\
\mathrm{L}\end{array}$ & Loading \\
\hline
\end{tabular}

Table1: Statistical values of the used parameters for design the sections of reinforced concrete [17-20].

\section{Limit function and safety index equation}

Eqn. 4 shows the limit state function which is used to the safety design of concrete beams under the simultaneous effects of bending, shear, and torsion.

$$
G=R-S ;\left\{\left\{M_{s} \leq M_{r} \quad, V_{s} \leq V_{r}, T_{s} \leq T_{r} \quad\right\}\right\}
$$

After employing Eqn. (4), in order to predict the safety index $(\beta)$, the values of $\mathrm{R}$ (resistance surface) and $\mathrm{S}$ (load surface) are calculated for the three mentioned states (bending, shear and torsion) using Hasofer-Lind equation [17-18]. Eqn. 5 shows the value of the safety index [18]. In this study, the safety index is calculated for current limit states functions using MonteCarlo simulation

$$
\text { Betaindex }=\frac{\operatorname{mean}_{\mathrm{R}}-\text { mean }_{\mathrm{S}}}{\sqrt{\sigma_{\mathrm{R}}^{2}+\sigma_{\mathrm{s}}^{2}}}
$$

\section{Safety surface of shear-torsion}

Based on Eqn. (4), by limiting the left side of Eqn. (6) to a specified value $\left(\varnothing\left(\frac{v_{c}}{b_{w} * d}+\frac{2}{3} \sqrt{f_{c}^{\prime}}\right)\right.$ the combination of simultaneous effects of shear and torsion can be achieved for different cross-sections. 


$$
\frac{V_{u}}{b_{w} * d}+\frac{T_{u} *\left(b_{w}+d\right) * 2}{\left(b_{w} * d\right)^{2} * 1.7}<\varnothing\left(\frac{v_{c}}{b_{w} * d}+\frac{2}{3} \sqrt{f_{c}^{\prime}}\right)
$$

$V_{u}, T_{u}$ s the ultimate shear and torsion demand and $v_{c}$ points to the shear strength of concrete. $b_{w}, d, f_{c}^{\prime}$ are the width of the web, the effective depth of the beam, and 28-day compressive strength of concrete, respectively. Estimation of the safety surface of ACI concrete standard for shear and torsion is as follows: First, the value of shear force, torsion, and bending moment are calculated according to the type of cross-section (L, T and rectangular shaped) using Eqn. (1-3). The method of calculation is such that a constant value for the dead load is devoted, and the live load is: live load $=\mathrm{dead}$ load* ${ }^{*}$ tio $=(1$ t) $/ t$ ). For this purpose, $t$ is changed from 0.40 to 1.0 Then, the amount of the live load is calculated. The amount of shear load is obtained from the sum of the live load to the dead load and finally, by considering the Eqn. (2) the amount of nominal shear steel required is obtained. Applying the value of the total moments on the beam (dead load moment + live load moment) and using Eqn. (3), the nominal required torsion steel is obtained. The method of calculating the total moments exerted on the beam is similar to the shear state and is practical by considering the ratio proposed by some researchers [12-13]. The limit state functions considered for solving the problem by taking the special formulas presented in ACI standard for shear, torsion and the combination of shear and torsion. Eqn. $7-9$ show the torsion shear limit state function.

$$
\begin{aligned}
& A C I G_{V}=\frac{V_{r}}{b_{w} * d}-\frac{V_{s}}{b_{w} * d}>0 \\
& A C I G_{T}=\frac{T_{r} *\left(b_{w}+d\right) * 2}{\left(b_{w} * d\right)^{2} * 1.7}-\frac{T_{s} *\left(b_{w}+d\right) * 2}{\left(b_{w} * d\right)^{2} * 1.7}>0 \\
& A C I G_{V \& T}=\frac{v_{u}}{b_{w} * d}+\frac{T_{u} *\left(b_{w}+d\right) * 2}{\left(b_{w} * d\right)^{2} * 1.7}-\frac{v_{s}}{b_{w} * d}+\frac{T_{s} *\left(b_{w}+d\right) * 2}{\left(b_{w} * d\right)^{2} * 1.7}>0
\end{aligned}
$$

In the above equations, the $\mathrm{S}$ index is the load and moment exerted on the cross-section (demand), $\mathrm{R}$ is the resistance surface of the cross-section (capacity). In sections 2-3 to 2-5, different levels of standard are presented for various combinations of forces. $A C I G_{V \& T}$ is limit state function for shear and torsion as well as $A C I G_{V}$ and $A C I G_{T}$ is shear and torsion limit sate function, respectively.

\section{The safety surface of bending-torsion}

To investigate the safety surface of the ACI standard, the values of torsion and bending steel are calculated using Eqns. (1) to (3). After calculating the values of the bending moment and the applied live and dead loads, a limit function as in Eqns. (10) and (11) are considered.

$$
\begin{aligned}
& A C I G_{B}=A_{s} * f_{y} *\left(d-\frac{A_{s} * f_{y}}{1.7 * f_{c} * b^{*} d}\right)-M_{s}>0 \\
& A C I G_{B \& T}=\frac{M_{r} * c}{I}+\frac{T_{r} *\left(b_{w}+d\right) * 2}{1.7 *\left(b_{w} * d\right)^{2}}-\frac{M_{s} * c}{I}+\frac{T_{s} *\left(b_{w}+d\right) * 2}{\left(b_{w} * d\right)^{2} * 1.7}>0
\end{aligned}
$$

In Eqns. 10 and 11, index $S$ refers to the effects of the loads (live + dead), and index $R$ points to the resistance against the exerted loads. $A C I G_{B \& T}$ is limit state function for bending and torsion as well as $A C I G_{B}$ and $A C I G_{T}$ are bending and torsion limit sate functions, respectively.

\section{The safety surface of bending-shear}

The amount of the required steel for three states was calculated in the previous sections. As well, the amount of the forces acting on the cross-section and the strength of the cross-section are obtained for three states of shear, torsion, and bending. In order to consider the combination of the bending and shear state $\left(G_{V \& B}\right)$, Eqn. 12 is used. 


$$
A C I G_{V \& B}=\left(\frac{V_{r}}{b_{w} * d}+\frac{M_{r} * C}{I}\right)-\left(\frac{V_{s}}{b_{w} * d}+\frac{M_{s} * C}{I}\right)>0
$$

The safety surface of bending-torsion-shear

The following limit sate function $\left(A C I G_{V, B \& T}\right)$ is considered to obtain the safety surface of the ACI standard for three states of shear, bending, and torsion.

$$
A C I G_{V, B \& T}=\left(\frac{M_{r} *_{c}}{I}+\frac{T_{r} *\left(b_{w}+d\right) * 2}{1.7 *\left(b_{w} * d\right)^{2}}+\frac{V_{r}}{b_{w} * d}\right)-\left(\frac{M_{s} * c}{I}+\frac{T_{s} *\left(b_{w}+d\right) * 2}{\left(b_{w} * d\right)^{2} * 1.7}+\frac{V_{s}}{b_{w} * d}\right)>0
$$

In Eqn. 13, three states of shear, bending and torsion effect appear simultaneously and by considering this limit state function, the safety surface is predicted.

\section{Sections and dimensions}

In order to calculate the beta index of $\mathrm{T}$, $\mathrm{L}$, and the rectangular cross-section beams, specified geometrical futures are assumed as shown in Fig. 1 and Tab. 2. The distributed load $(25 \mathrm{kN} / \mathrm{m})$ is exerted on the beam length. Cross-sections of the mentioned beams are selected in such a way that the area of the T-shape section is twice that of L-shape section and the rectangular section area was $b_{w} * d$.
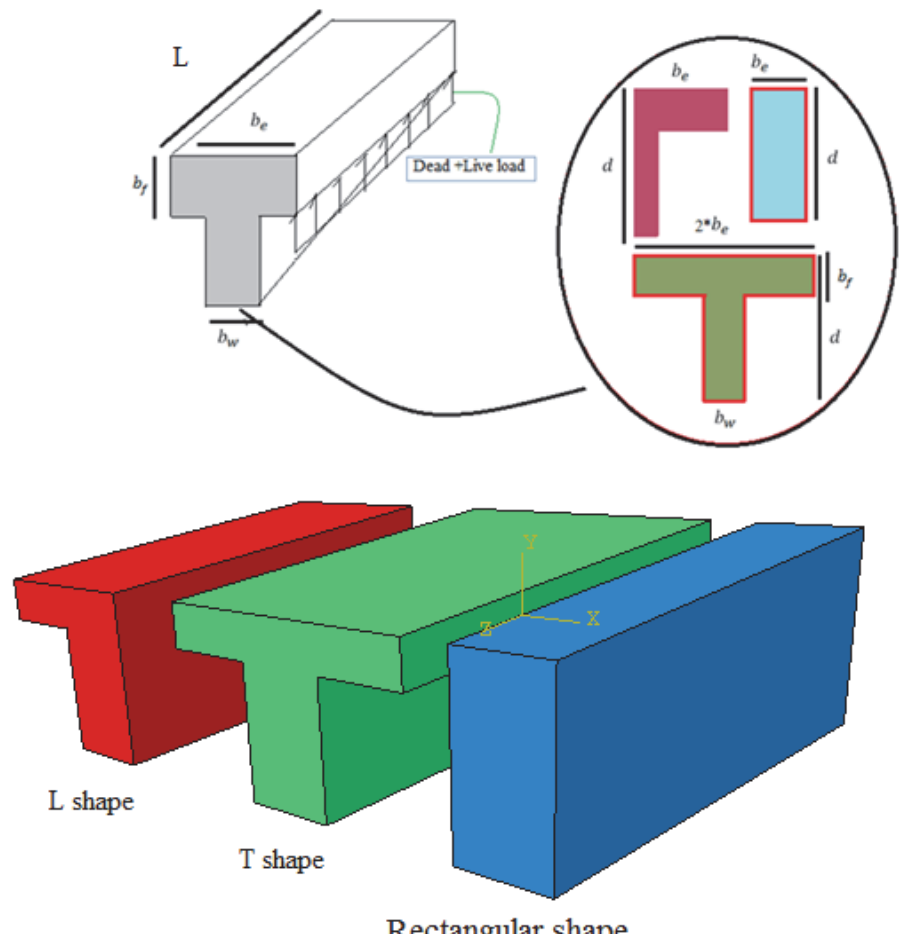

Figure 1: Schematic figure of the L, T, and Rectangular sections

\begin{tabular}{ccccc}
\hline $\mathrm{b}_{\mathrm{w}}(\mathrm{mm})$ & $\mathrm{q}_{\mathrm{D}}(\mathrm{kN} / \mathrm{m})$ & $\mathrm{f}_{c}^{\prime}(\mathrm{MPa})$ & $\mathrm{b}_{\mathrm{c}}(\mathrm{mm})$ & $\mathrm{f}_{\mathrm{y}}(\mathrm{MPa})$ \\
450 & 25 & 21 & 850 & 420 \\
$\mathrm{~b}_{\mathrm{f}}(\mathrm{mm})$ & $\mathrm{d}(\mathrm{mm})$ & $\mathrm{L}(\mathrm{mm})$ & $M_{L}=$ ratio $* M_{D} ;$ ratio $=(1-t) / t$ \\
200 & 400 & 2000 & \multicolumn{2}{c}{$0.4-1.0$} \\
\hline
\end{tabular}

Table 2: The nominal parameters of this study 


\section{RESUlts}

he results are presented in two sections. The first part of the results is devoted to the estimation of the safety indexes using the proposed method. The main goal is presenting an approach to the safe design of beams instead of the traditional method. In the second part, the load resistance factors are calculated based on estimated safety indexes. The presented method could be easily applied to other international design codes. Namely, the safety indexes are estimated without using specific standards, e.g. ACI. On the other hand, the estimation of safety indexes is independent of any regulation.

\section{The safety surface of standard for states of torsion-shear}

The safety index is calculated considering statistical values (mean, covariance and pdf) as given in Tabs. 1 and 2 and the limits state functions. The following flowchart shows the calculation of the safety indexes and load factors.

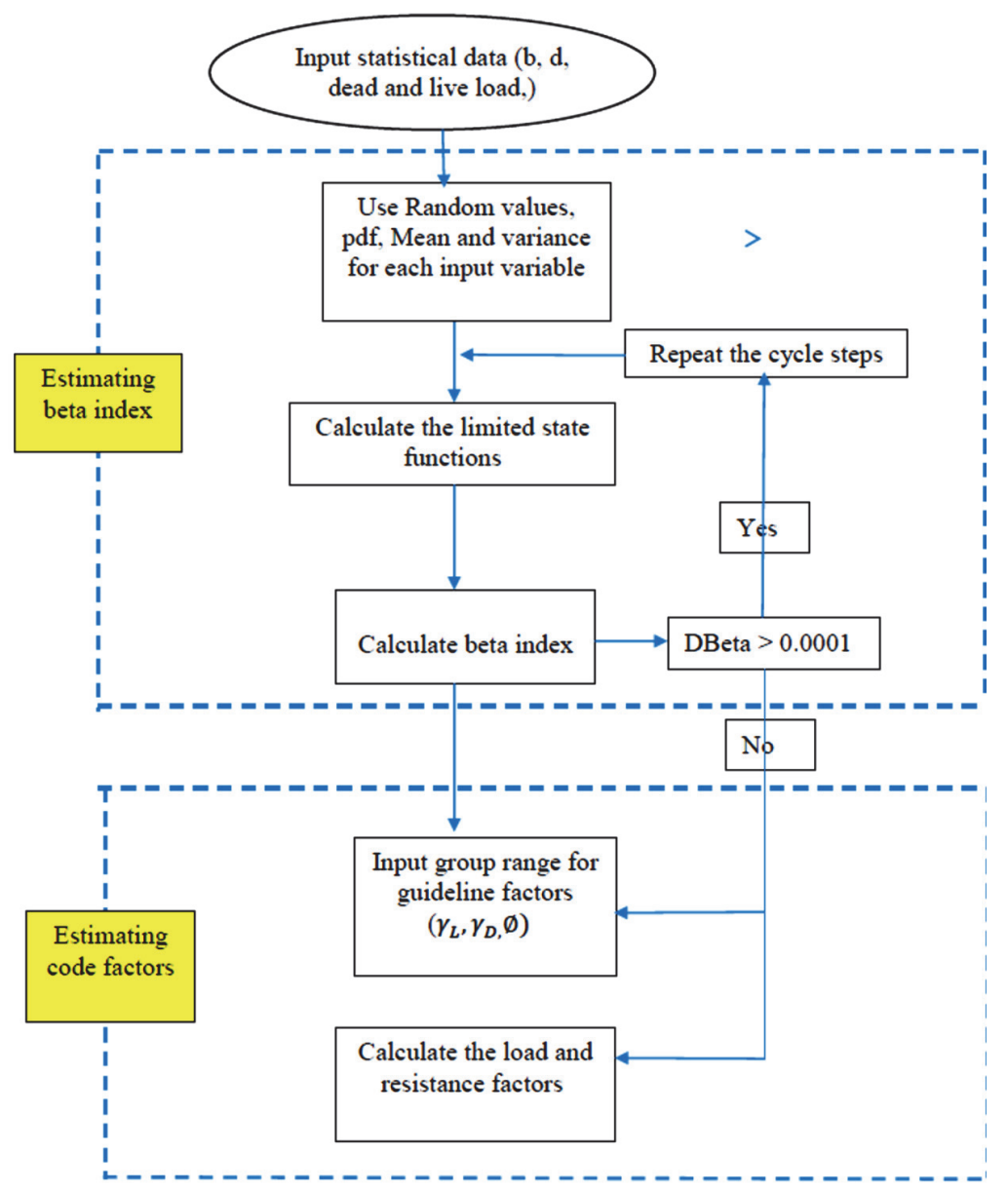

Figure 2: Flowchart of computer code to estimate the beta index and load factors.

Fig. 3 shows the beta indexes vs $t$ values for different cycle numbers, as seen from the figure the cycle number 15000 for all values of $\mathrm{t}$ is good enough for the next calculations. As well, Fig. 4 shows the beta index for all types of cross-sections for shear-torsion combination. In this combination, the safety index has higher than the individual actions because of the application of strength reduction and load resistance factors in the design procedure. After the combined mode, the designed beam for shear actions, the sections have the maximum beta value, and finally, the beta in the torsional design of beams has the lowest value, which is similar to the results of previous studies [20,23]. However, the safety indexes range is between 2.65 to 3.35 , and according to the suggestions of the previous references, the safety index value is suitable for the safe design. 


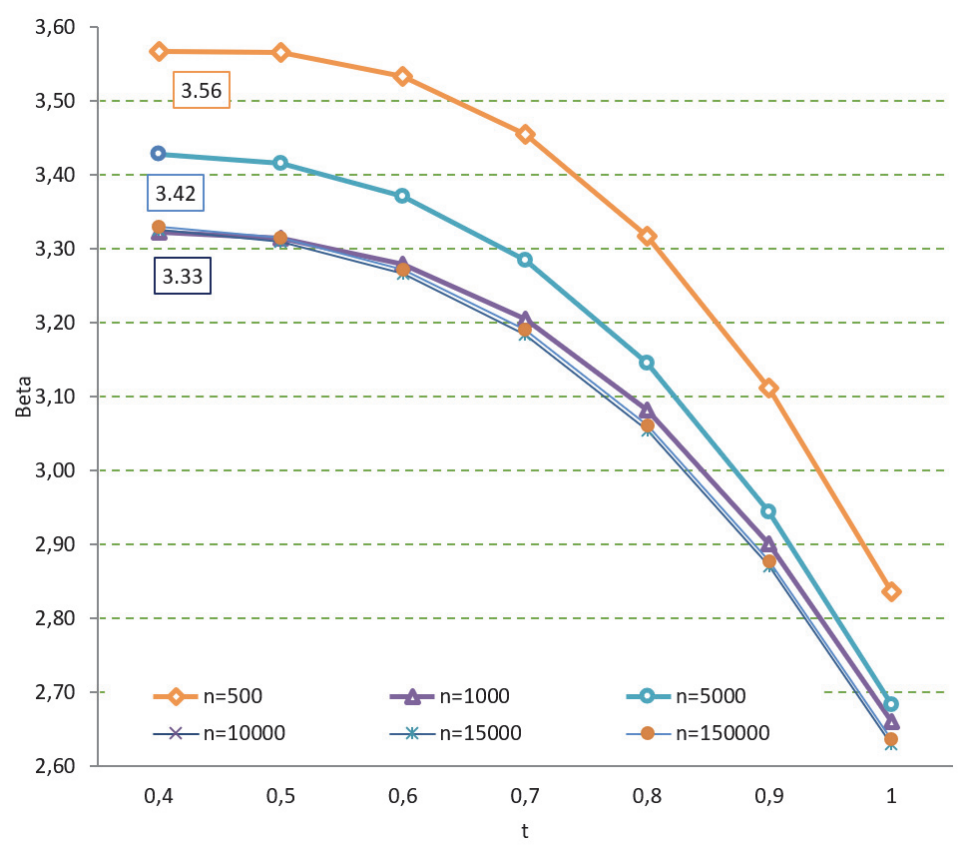

Figure 3: ACI beta index for shear-torsion for different Monte Carlo cycles

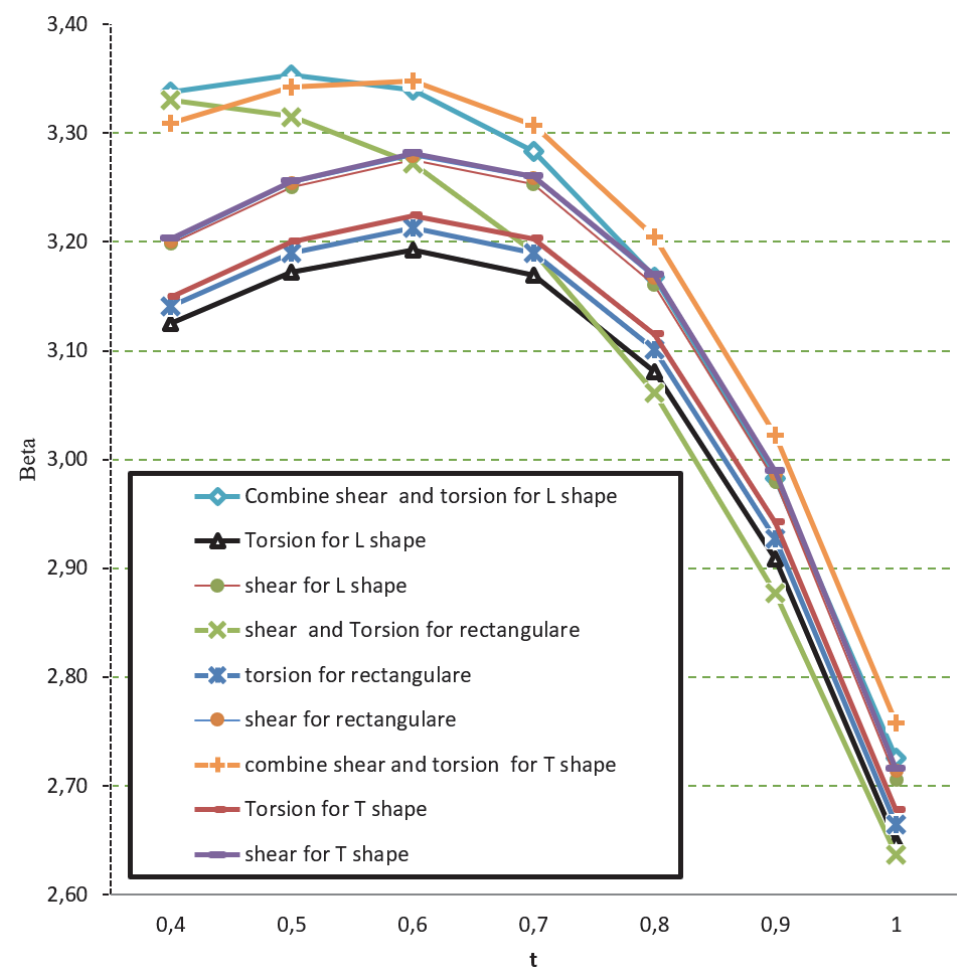

Figure 4: ACI beta index for shear-torsion combination.

\section{ACI safety surface for bending-torsion}

In this section, the equations presented in section 2-3 are employed and the ACI safety index is calculated for bending and torsion states. Fig. 5 shows the beta index for bending and torsion state for three studied cross-sections. The standard surface of ACI for torsion is from 2.50 to 3.20 and the standard surface of ACI concrete for bending is between $2.50-4.15$. The standard surface of ACI concrete for bending and torsion is between the values of bending and torsion and it is close to bending state, and the average value is 3.70 for bending-torsion. The maximum value of the safety index for the combination of torsion-bending occurs at $\mathrm{t}=0.6$. 


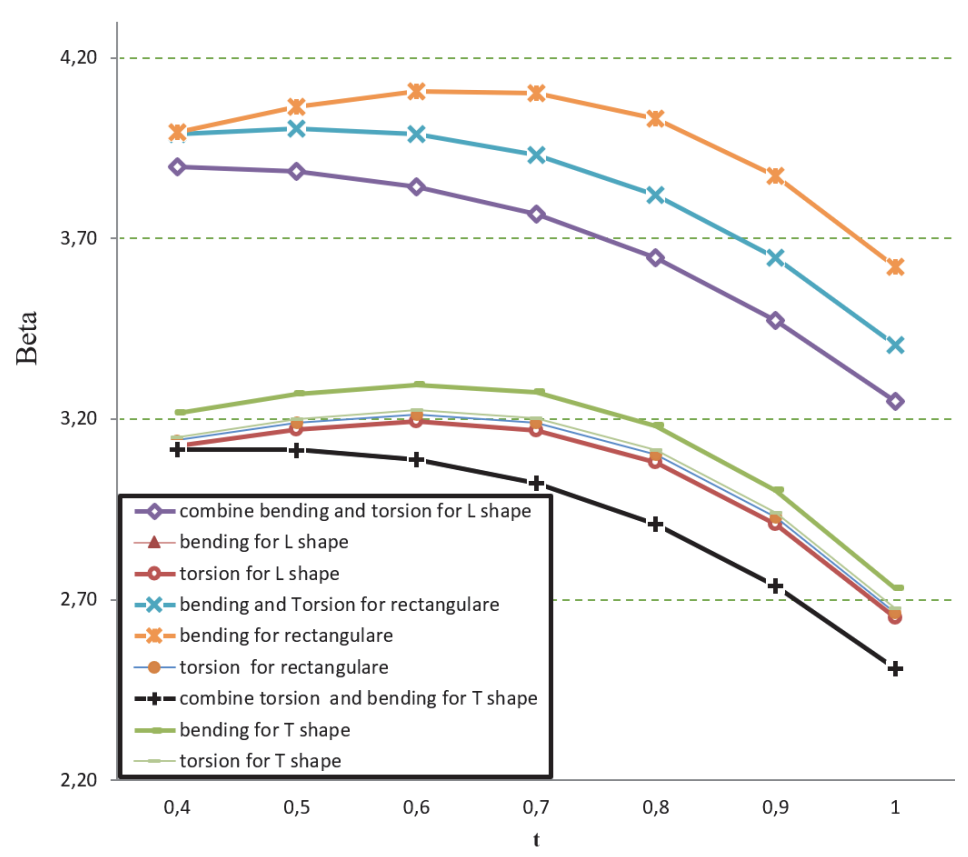

Figure 5: ACI beta index for torsion-bending.

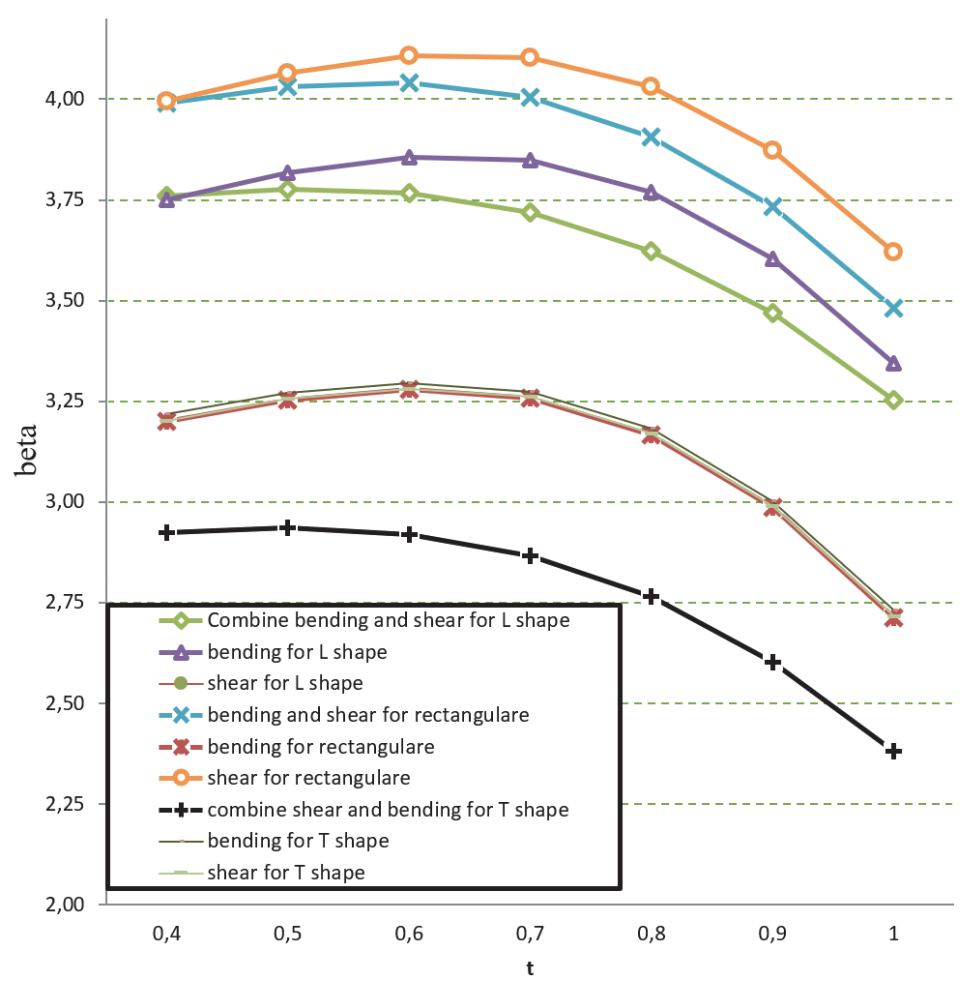

Figure 6: ACI beta index for bending-shear.

ACI safety surface for bending-shear

Fig. 6 shows the standard safety surface of ACI concrete for shear and bending. The ACI standard surface for combination states (shear and bending) is close to the shear state.

\section{ACI safety surface for bending-shear-torsion}

The combination of shear, bending and torsional states is carried-out using Eqn. 13. Graph 7 shows the safety index for the three combination states. According to this figure, the ACI beta indexes for L, rectangular, and L cross-sections are 4.05, 
3.91 and 3.13, respectively. The maximum beta value corresponds to $t=0.5$ and afterward, the safety index is decreased due to the decreasing of the live load and the impact of the live load coefficient. The variations of the safety index in the Tshaped cross-sections are higher than the other ones, and the maximum safety index is obtained for the slab-shaped sections.

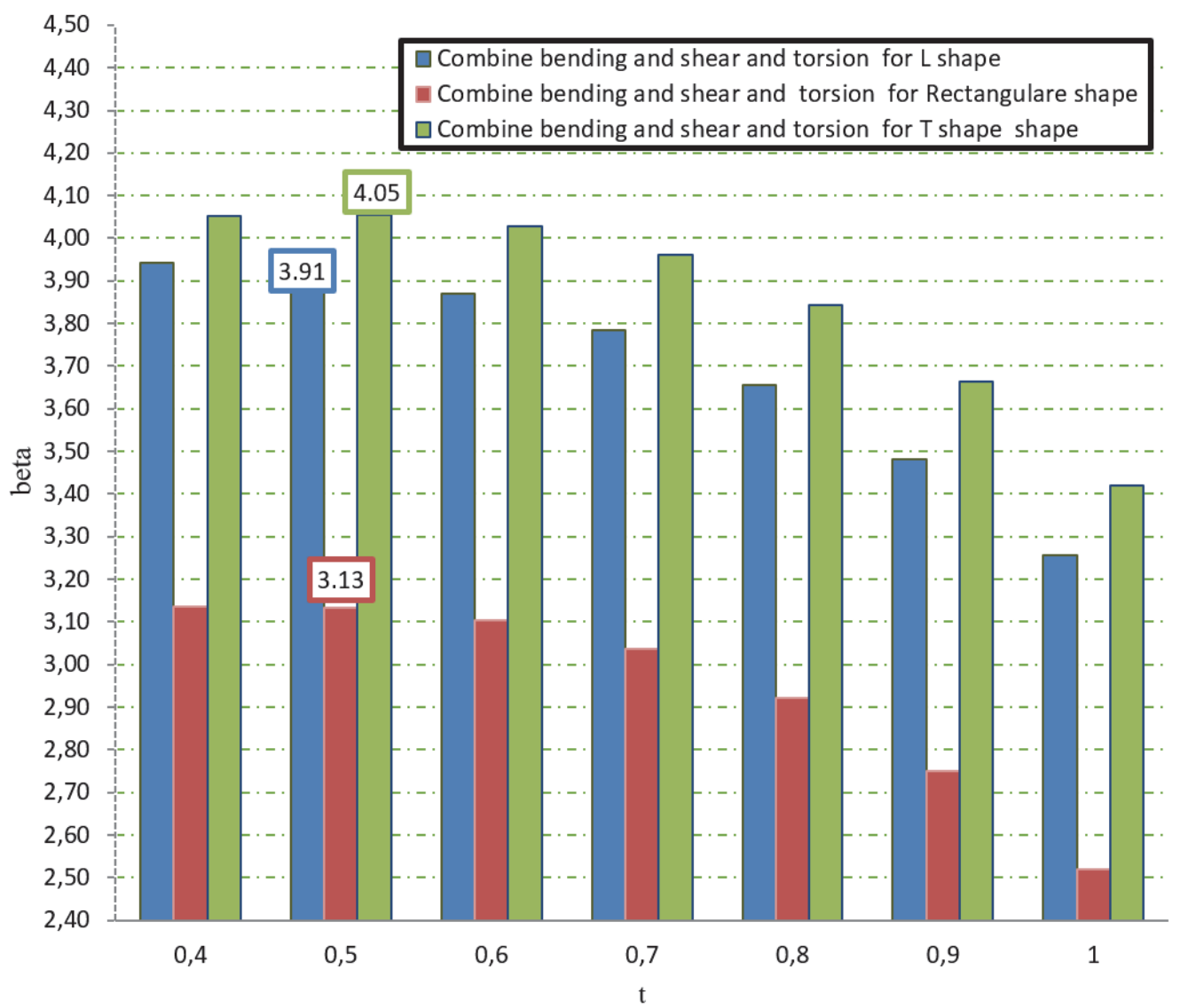

Figure 7: ACI beta index for shear-bending -torsion

\section{Estimation of the standard safety factors for limit STATES (shear-torsion-bending)}

In this section, the values of load resistance and strength reduction factors are estimated, and for them, wide ranges are proposed. Then, based on these ranges the safe design of the studied beams is conducted without using constant standard code coefficients. Therefore, the presented procedure could be implemented for all standards. However, to show the validation of the proposed method, the estimations are based on the ACI code. To obtain the safety index, firstly, a wide range of strength reduction factors were considered and entered into the developed MATLAB code as an input variable. Next, the limit state equations in ACI standard were used, and safety indexes were calculated. Figs. 8 to 10 show the coefficients obtained from Monte Carlo simulation and the beta index. The reduction factors have a significant influence on the beta indexes. Tab. 3 shows factors for (dead load, live load, and resistance reduction factors) that have been assumed for the calculated beta index. In this research for calculating the beta indexes, eleven groups of factors were used.

\begin{tabular}{cccccccccccc}
\hline Group factor & 1 & 2 & 3 & 4 & 5 & 6 & 7 & 8 & 9 & 10 & 11 \\
Live load resistance factor $\left(\boldsymbol{\gamma}_{\boldsymbol{L}}\right)$ & 1.40 & 1.42 & 1.44 & 1.46 & 1.48 & 1.50 & 1.52 & 1.54 & 1.56 & 1.58 & 1.60 \\
Dead load resistance factor $\left(\boldsymbol{\gamma}_{\boldsymbol{D}}\right)$ & 1.00 & 1.02 & 1.04 & 1.06 & 1.08 & 1.10 & 1.12 & 1.14 & 1.16 & 1.18 & 1.20 \\
Strength reduction factors $(\varnothing)$ & 0.70 & 0.72 & 0.74 & 0.76 & 0.78 & 0.80 & 0.82 & 0.84 & 0.86 & 0.88 & 0.90 \\
\hline
\end{tabular}

Table 3: Load and resistance factors for calculating the beta indexes. 
Fig. 8 shows the maximum beta index corresponds to $t=0.40$ and 0.50 . For all values of $t$ and load resistance factors, the safety indexes are between 3.55 to 4.65. As well, the safety index is decreased due to the reduction of the live load effect or increasing of $\mathrm{t}$ values. Furthermore, the indexes are reduced by increasing the load and resistance factor by a mild slope. As a result, for rectangular type cross-section, the variations of the safety indexes are more dependent on the values of $\gamma_{L}, \gamma_{d}, \varnothing_{c}$.

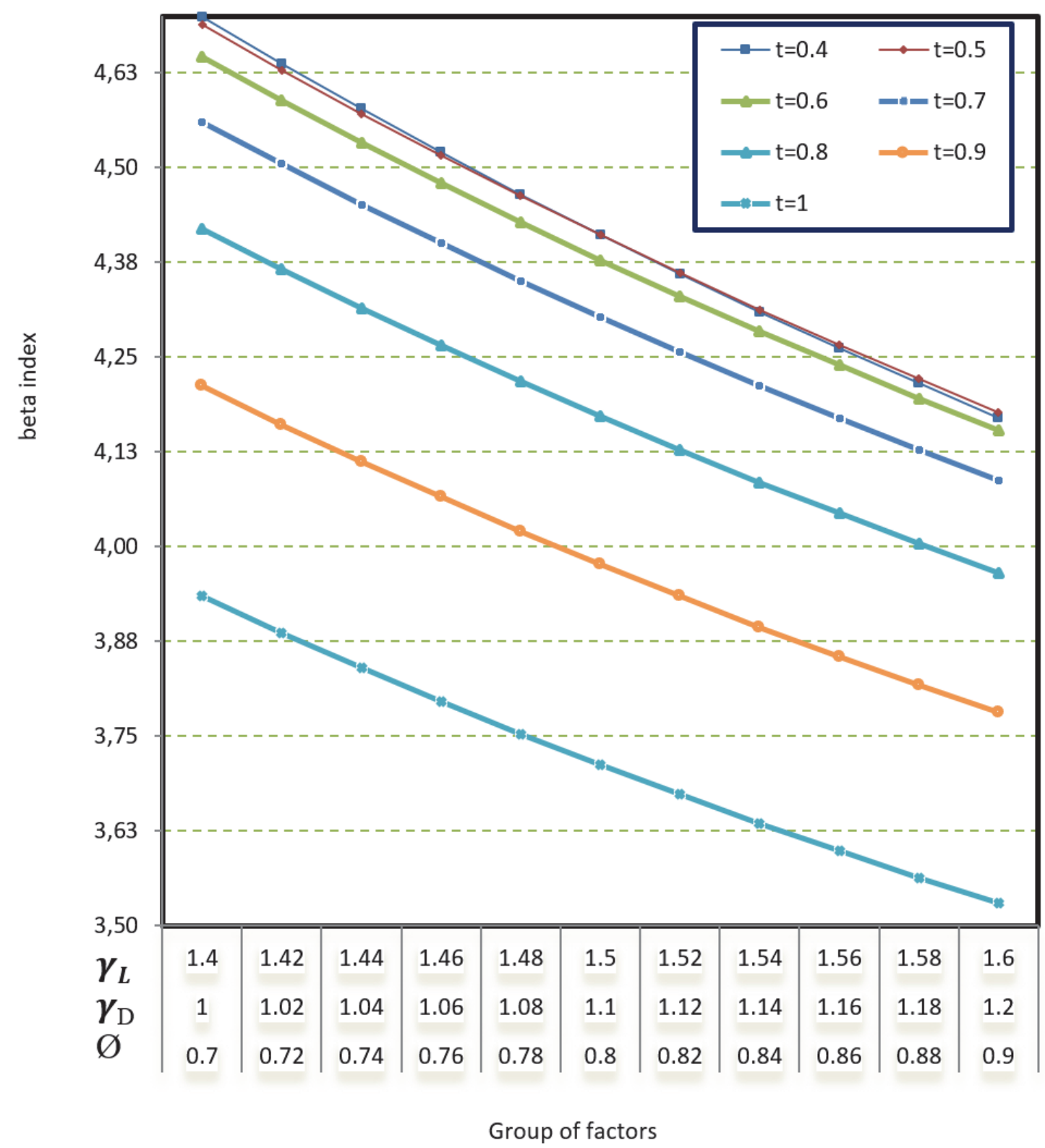

Figure 8: Prediction of load and resistance factors for the rectangular beam in combined state

As seen from Fig. 9 the maximum beta index corresponds to $t=0.40$ and 0.50 . For all values of $t$ and load resistance factors, the safety indexes are between 3.15 to 4.00, which there are less than indexes for rectangular cross-section. As well, for Lshaped beams, the safety indexes are remained constant by variation of the load resistance factors. As a result, for $\mathrm{L}$ type cross-sections, the variations of the safety indexes are independent of the values of $\gamma_{L}, \gamma_{d}, \varnothing_{c}$. 
Fig. 10 represents the maximum beta index corresponds to $t=0.40$ and 0.50 . For all values of $t$ and load resistance factors, the safety indexes are between 2.65 to 3.70. As well, the safety index is decreased due to the reduction of the live load effect or increasing of $\mathrm{t}$ values. Furthermore, the indexes are reduced by increasing the load and resistance factors by the mild slope. As a result, similar to rectangular type beams, for $\mathrm{T}$ type cross-sections, the variations of the safety indexes are more dependent on the values of $\gamma_{L}, \gamma_{d}, \varnothing_{c}$.

Figs. 8 to 9 clearly show that the safety indexes for T type beams are smallest and L type beams have better performance. Generally, the rectangular beams have the highest safety factors. Because the torsion on these types of beams has less contribution and the bending moment has a significant effect.

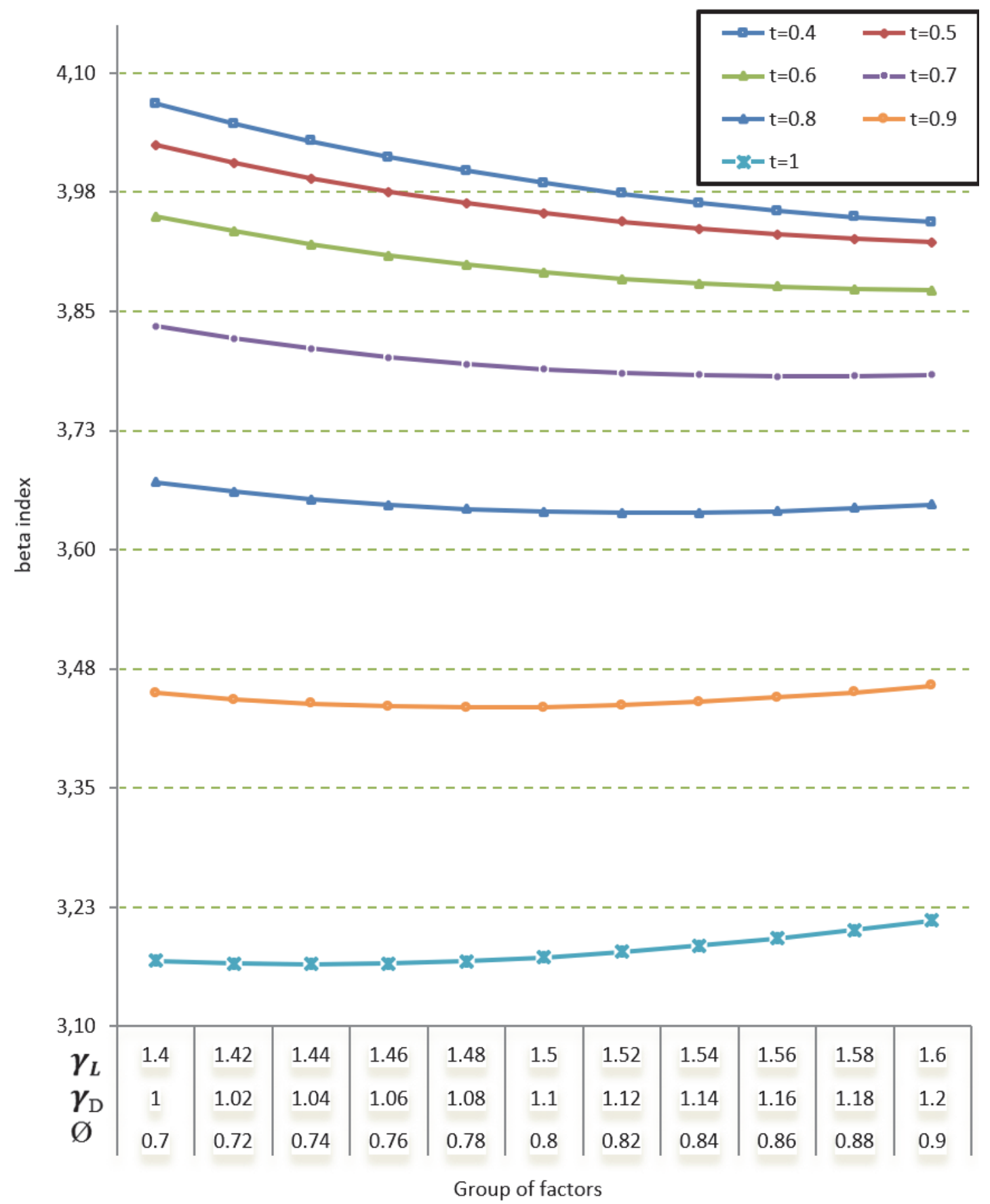

Figure 9: Prediction of load and resistance factors for the L section beam in combined state 


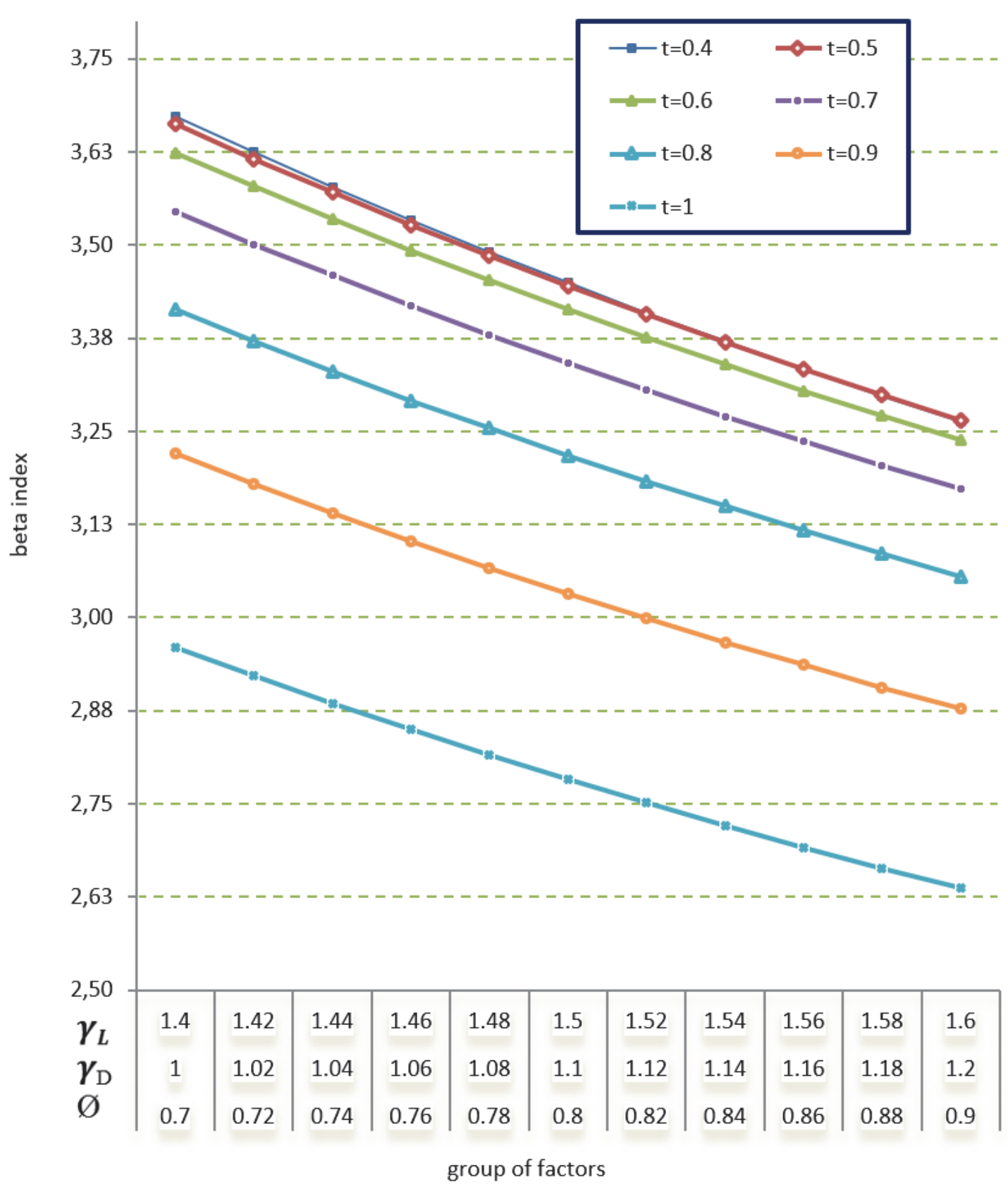

Figure 10: Prediction load and resistance factors for T section beam in combined state

\section{Discussion}

he safety surfaces of the ACI concrete standard for combined limit sates ( torsion-shear-bending) were studied in this research and the ACI standard beta indexes were obtained. In the combined modes, the beta coefficient is greater than 3.0 for the $\mathrm{L}$ and rectangular cross-sections, while for the $\mathrm{T}$ cross-section, the safety index is less than 3.0 for $\mathrm{t}>0.5$, and according to the suggested references, the safety coefficients should be greater than 2.8 for the bending design of cross-sections and greater than 2 for the design of shear and torsion, which is somewhat the boundary points. Figs. 11 and 12 show the maximum and average beta indexes for all limit states for three studied cross-sections. 


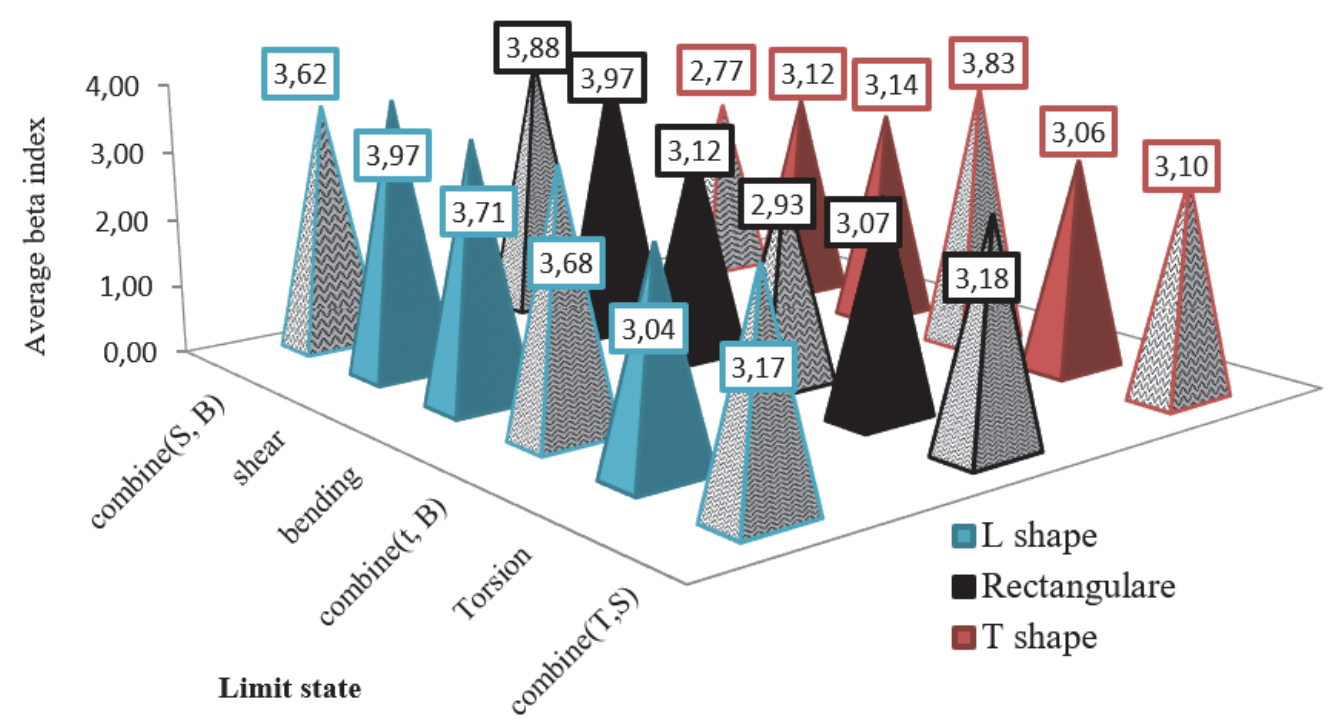

Figure 11: Average ACI beta indexes for different cross-sections.

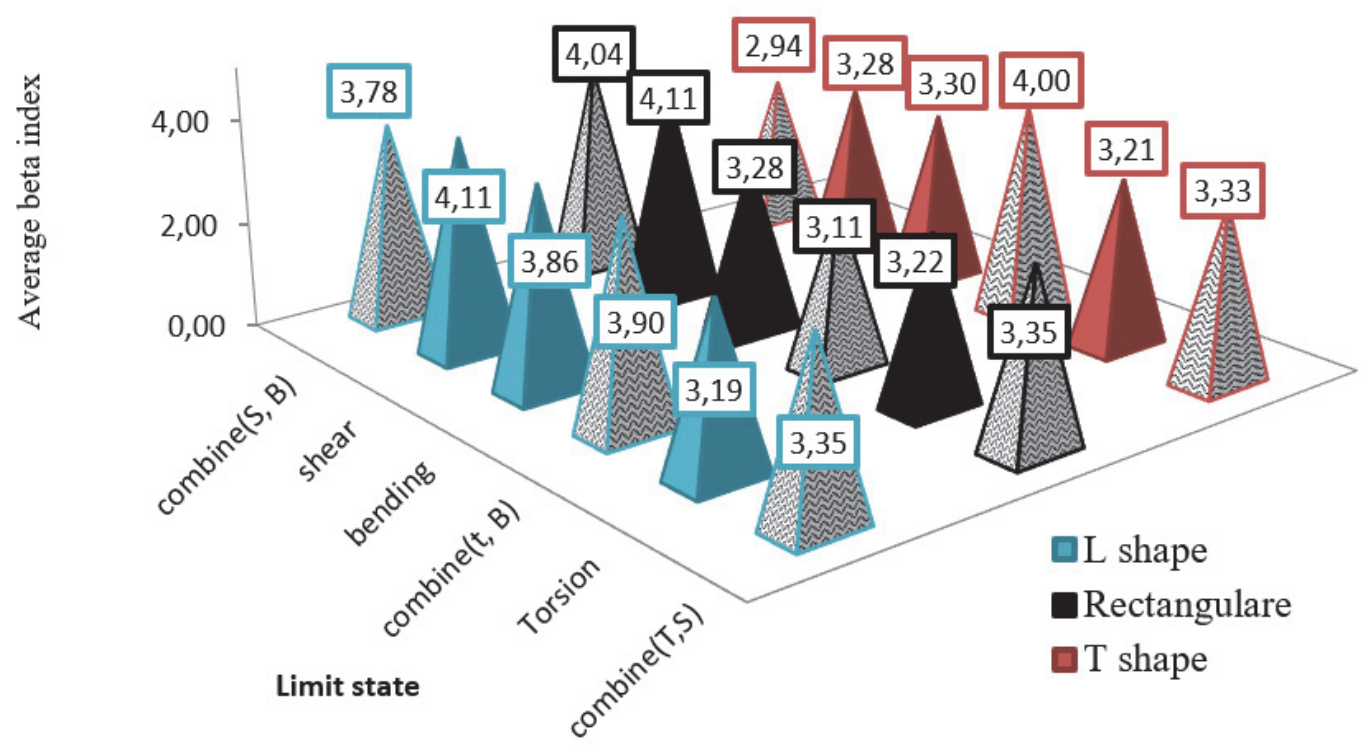

Figure 12: Maximum ACI beta indexes for different cross-sections.

\section{CONCLUSION}

$\mathrm{B}$ ased on the obtained results the following conclusions could be drawn:

In all cross-sections, the obtained beta index for the combination of bending-shear is between shear and bending state such that the beta index is higher than the bending state and lower than the torsion state.

- The beta index for a combination of bending-torsion is between torsion and bending state such that the beta index is higher than the bending state and lower than the torsion state. This surface is close to the bending state which means bending equations have a significant effect on the combination surface. 
- Beta index for a combination of shear-torsion is between torsion and this surface is close to shear state which means shear equations have a significant effect on the combination surface.

- For all combination states (shear - torsion and bending -torsion), the beta indexes are greater than 3 which shows the beams are designed safety. According to previous research [20], the values of the beta index should be greater than 2.8 due to the design beam in bending and shear limit state safety.

- In combined state(shear bending and torsion), the value of the beta index has the highest value in comparison with other limit states (shear - bending, shear - torsion and bending - torsion ) which shows the ACI equations adequately guarantee the safe design.

\section{Disclosure}

he authors have no conflict of interest to declare.

\section{ACKNOWLEDGMENT}

he second author acknowledges the support from Malayer University when he was an assistant professor of civil engineering from September 2008 to June 2019.

\section{REFERENCES}

[1] Ellingwood, B. R.and Ang, A. H. (1974). Risk-based evaluation of design criteria. Journal of the Structural Division, 100 (Proc. Paper 10778).

[2] Bentz, E. C., Vecchio, F. J.and Collins, M. P. (2006). Simplified modified compression field theory for calculating shear strength of reinforced concrete elements. ACI Materials Journal, 103(4), pp.614-621

[3] Porco, F., Uva, G., Sangirardi, M.and Casolo, S. (2013). About the reliability of punching verifications in reinforced concrete flat slabs. The Open Construction and Building Technology Journal, 7(1), pp. 123-133

[4] Jensen, D.F. (2014). Reliability analysis for shear in lightweight reinforced concrete bridges using shear beam database, M.Sc. Thesis, Utah State University.

[5] Backes, M. R., Fernández Ruiz, M.and Muttoni, A. (2014). Interaction between in-plane shear forces and transverse bending moments in concrete bridge webs. In Proc. of the 10th fib International Ph.D. Symposium in Civil Engineering, Quebec (No. CONF, pp. 403-408).

[6] Nowak, A. S.and Szerszen, M. M. (2003). Calibration of design code for buildings (ACI 318): Part 1-Statistical models for resistance. ACI Structural Journal, 100(3), pp. 377-382.

[7] Uva, G., Porco, F., Fiore, A.and Mezzina, M. (2013). Proposal of a methodology for assessing the reliability of in situ concrete tests and improving the estimate of the compressive strength. Construction and Building Materials, 38, pp. 7283.

[8] Pérez-Rocha, L. E., Fernández, M. A., Manjarrez, L. E., Maldonado, J. D.and Esteva, L (2014). A simplified methodology to obtain reliability indexes for calibration of design code for buildings, 4th International Conference on Computational Methods in Structural Dynamics and Earthquake Engineering, Kos Island, Greece.

[9] Abejide, O. S. (2014). Reliability Analysis of Bending, Shear and Deflection Criteria of Reinforced Concrete Slabs. Nigerian Journal of Technology, 33(3), pp. 394-400.

[10] Al-Ansari, M. S. (2015). Reliability and flexural behavior of triangular and T-reinforced concrete beams. International Journal of Advanced Structural Engineering (IJASE), 7(4), pp. 377-386.

[11] Bastidas-Arteaga, E. (2018). Reliability of reinforced concrete structures subjected to corrosion-fatigue and climate change. International journal of concrete structures and materials, 12(1), pp. 10-21. 
[12] Jafar.F, Akbari. Jand Jahanpour, A. (2017). Evaluation of Safety Index and Calibration of Load and Resistance Factors for Reinforced Concrete Beams under Bending, Shear, and Torsion Demands, Journal of Structural and Constructional Engineering, 3(4), pp. 49-64.

[13] Akbari, J.and Jafari, F. (2018). Calibration of Load and Resistance Factors for Reinforced Concrete. Civil Engineering Infrastructures Journal, 51(1), pp. 217-227.

[14] Słowik, M., Skrzypczak, I., Kotynia, R.and Kaszubska, M. (2017). The application of a probabilistic method to the reliability analysis of longitudinally reinforced concrete beams. Procedia Engineering, 193, pp. 273-280.

[15] Huang, X., Sui, L., Xing, F., Zhou, Y.and Wu, Y. (2019). Reliability assessment for flexural FRP-Strengthened reinforced concrete beams based on Importance Sampling. Composites Part B: Engineering, 156, pp. 378-398.

[16] ACI Committee 318. (2015). Building Code Requirements for Structural Concrete (ACI 318M-14): An ACI Standard: Commentary on Building Code Requirements for Structural Concrete (ACI 318M-14). American Concrete Institute.

[17] Ellingwood, B., MacGregor, J. G., Galambos, T. V.and Cornell, C. A. (1982). Probability-based load criteria: load factors and load combinations. Journal of the Structural Division, 108(5), pp. 978-997.

[18] Nowak, A. S.and Collins, K. R. (2012). Reliability of structures. CRC Press .

[19] Choi, S. K., Grandhi, R.and Canfield, R. A. (2006). Reliability-based structural design. Springer Science \& Business Media .

[20] Mirza, S. A. (1998). Monte Carlo simulation of dispersions in composite steel-concrete column strength interaction. Engineering structures, 20(1-2), pp. 97-104.

[21] MATLAB (2016), The MathWorks, Inc., Natick, Release 2016.

[22] Badarloo, B.and Jafari, F. (2019). Numerical Study on the Effect of Concrete Grade on the CFT Circular Column's Behavior under Axial Load. Civil Engineering Journal, 5(11), pp. 2359-2376. 